\title{
Extraction Character of Small Molecular Compounds from Peanut Shell Guizhen Gong ${ }^{\mathrm{a}}{ }^{*}$, NaiBo Han ${ }^{\mathrm{b}}$ and Di Feng ${ }^{\mathrm{c}}$

\author{
School of Chemical Engineering, Xuzhou University of technology, Xuzhou 221018, China
} \\ a'ggz72@163.com, ${ }^{b} 903069091 @ q q . c o m,{ }^{c} 1290865003 @ q q . c o m$
}

\begin{abstract}
Keywords: Peanut Shell; ethanol; Acetone ; Petroleum ether; FTIR
\end{abstract}
\begin{abstract}
The extraction characteristics of small molecules from peanut shell with ethanol, acetone and petroleum ether were investigated. The extracts were detected and analyzed with infrared spectrum analysis (FTIR). The results show that the effect of ethanol extraction was better than acetone and petroleum ether. The total yield of ethanol extraction was $31.6 \%$, acetone $24.4 \%$, and petroleum $17.4 \%$. FTIR analysis showed that ethanol more easily enriched hydroxyl, benzene, C-O and fatty hydrocarbon $\mathrm{C}-\mathrm{H}$ structure, while the extraction of containing $\mathrm{C}=\mathrm{O}$ group was weaker than the other two solvents. The research has important basic theoretical significance in developing peanut shell with high added value.
\end{abstract}

\section{Introduction}

Peanut is known as one of the world's five major oil crops, which grows all over the world. China, as a big peanut producing country in the world, the planting area of peanut has been increasing year by year, and the output has reached 15 million tons, rank first in the world. Peanut shell, accounting for about $30 \%$ of the peanut weight, nearly 5 million tons each year are produced. In addition to a small amount of peanut shells used as feed, fuel and chemical raw materials (such as acetone, acetic acid, furfural, etc. ), most of them were thrown away in vain, resulting in a great waste of resources. The peanut shell contains phytin, yellow pigment, xylan, luteolin, dietary fiber, xylitol, furfural, antioxidant, total phenolic compounds, if which can be comprehensively developed and utilized, not only can develop a new kind of resource[1-6], but also can reduce the environmental pollution of the waste, so the research and development of peanut shell the potential and huge economic benefit. The key problem affecting its processing and utilization is the insufficient understanding of its organic structure.

In this paper, peanut shell powder was extracted with different polar organic solvents (ethanol, acetone and petroleum ether) to study its organic structure and provide theoretical basis for its high added value

\section{Experimental}

Materials. Peanut shell used in this study was collected from Xuzhou city, Jiangsu, China. It was washed with de-ionized water, and air-drying, then, which was ground to pass through 200 mesh sieve. All the raw materials were dried in an oven at $100{ }^{\circ} \mathrm{C}$ for $5 \mathrm{~h}$, and then stored in a desiccator at room temperature before using. All chemicals used in the experiment are analytical grade, obtained from the commercial source, and were used without further purification.

Experimental method. $1.5 \mathrm{~g}$ peanut shell dried were added into a modified Soxhlet's extractor, and extracted with $150 \mathrm{ml}$ 95\% ethanol, acetone and petroleum ether （PE） for $5 \mathrm{~h}$, respectively. The extraction liquids were cooled to room temperature, remove most of the solvent with a rotary evaporator under atmospheric pressure evaporation, then moved the concentrated liquid to the sample bottle, and the residual solvent evaporation to constant weight, and called extracts. The extracted residue was dried in a vacuum drying box and weighed. Then the next extraction were carried out, successively followed for 5 times.

The extracts gained were analyzed by FTIR spectroscopy (Alpha, Bruker company, German) using potassium bromide tableting method over a scan range of 500 to $4000 \mathrm{~cm}^{-1}$. 


\section{Results and Discussion}

Yield of Extraction. Extraction weights of three kind solvents were studied and is shown in Fig. 1. It is obvious that the extraction weights decreased in turn with the increase of the extraction times. Ethanol was the best solvent, acetone the second, PE has the worst extraction effect at each extraction. The total extraction yield of ethanol was $31.6 \%$, acetone extraction $24.4 \%$, and PE extraction was $17.4 \%$.

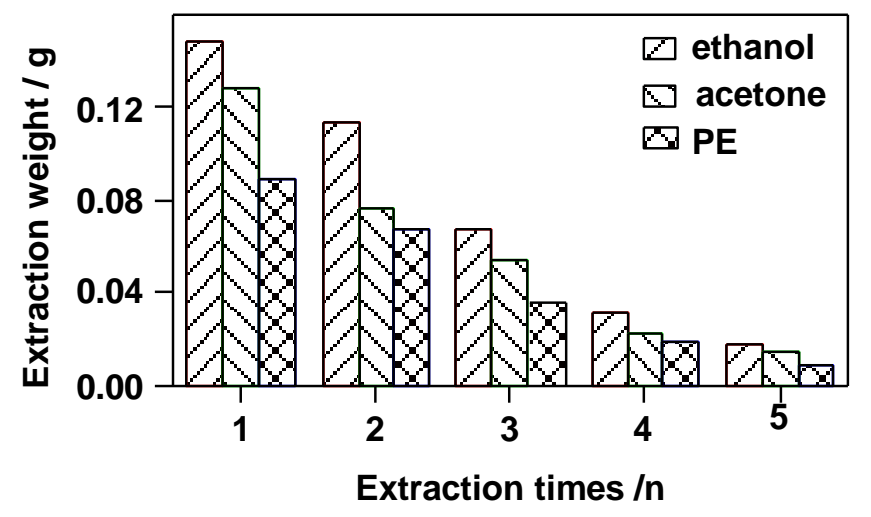

Fig. 1 Weight of different solvent extracts

FTIR Analysis. FTIR spectra of grading extracts was shown in Figure 2-4. As shown in Figures, The wide and strong absorption peak shown in Figure $3400 \mathrm{~cm}^{-1}$ attributed to stretching vibration of hydroxyl group, the ethanol extract is higher than those of acetone and petroleum ether extract, showing that there is more $\mathrm{OH}$ in the ethanol extract. At the same time, with the increase of the extraction times, the intensity of the absorption peak increases in turn. The peaks at $2925 \mathrm{~cm}^{-1}$ and $2827 \mathrm{~cm}^{-1}$ were the characteristic $\mathrm{C}-\mathrm{H}$ stretching modes of the aliphatic $-\mathrm{CH}_{3}$ and $-\mathrm{CH}_{2}$ groups, which increase with the increase of extraction times in the ethanol extract, while in acetone and petroleum ether extracts which were weaker in the third and fourth extracts. The wave at $1760 \mathrm{~cm}^{-1}$ was corresponded to carbonyl bond, which was weak in the ethanol extract and were higher at second times in the acetone and petroleum ether extracts, showing that the content of carbonyl functional group was higher in the second extracts of the acetone and petroleum ether extracts. The absorption peak about $1637 \mathrm{~cm}^{-1}$ is benzene ring skeleton $\mathrm{C}=\mathrm{C}$ stretching vibration, which of the ethanol extract was stronger than that of acetone and petroleum ether extract, and increased with the extraction times, showing that there are more benzene in ethanol extract, and gradually precipitated with the extraction time extended. Absorption at about $1130 \mathrm{~cm}^{-1}$ was assigned to $\mathrm{C}-\mathrm{O}$ asymmetry stretching, including alcohols, ethers, and esters bonds. Which in ethanol extract increased gradually with the increase of extraction times, while in acetone and petroleum ether extracts, the absorption was stronger in the second extraction. FTIR analysis of extracts at all levels shows that the dissolutions of various substances from peanut shell in three organic solvents are a gradual process. 


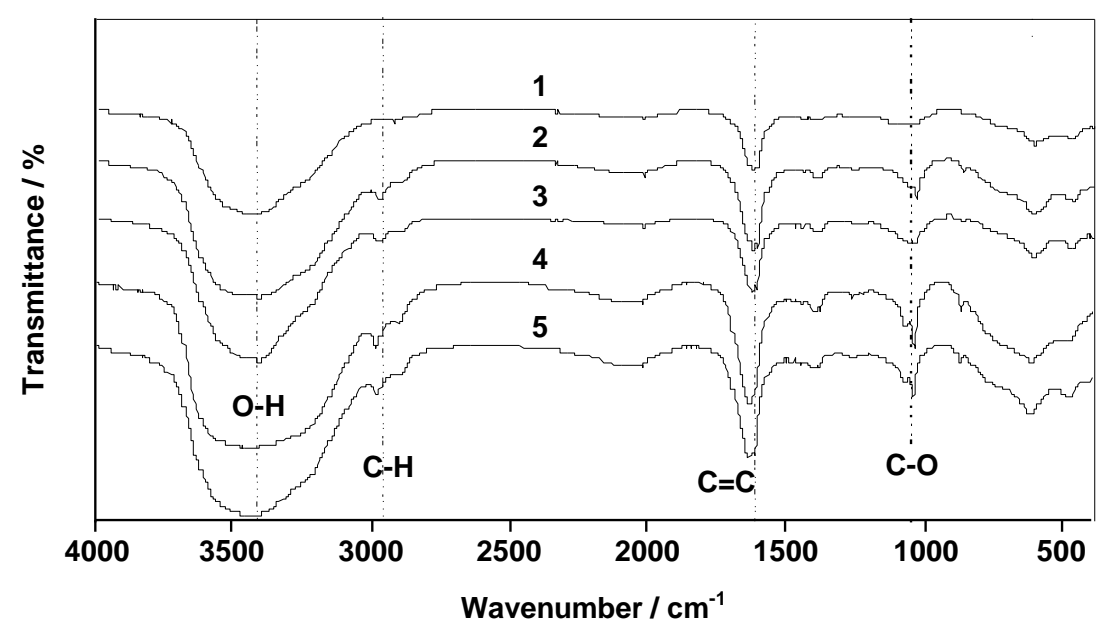

Fig. 2. FTIR spectra of ethanol extraction

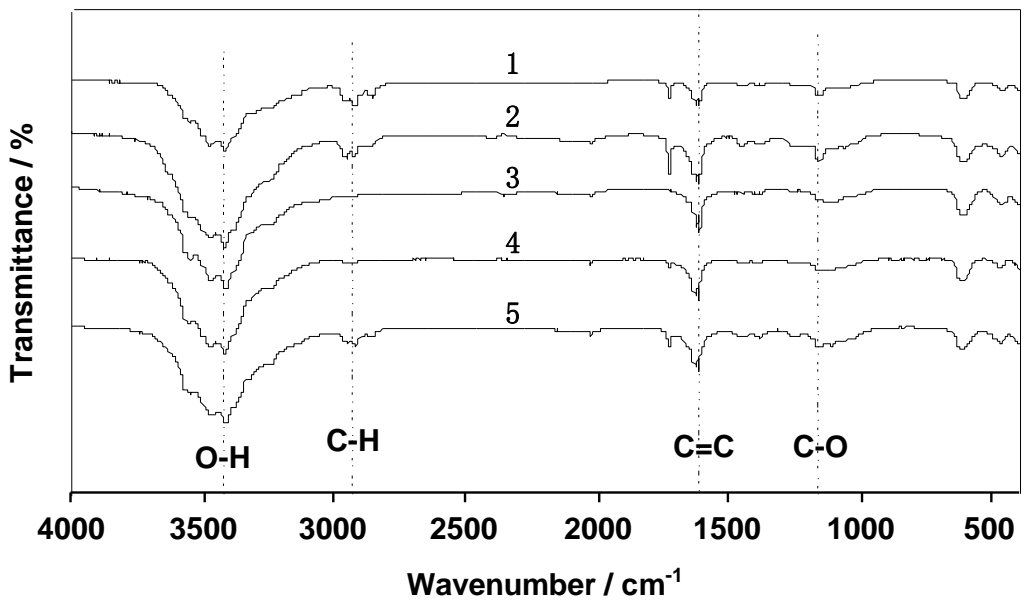

Fig. 3. FTIR spectra of acetone extraction

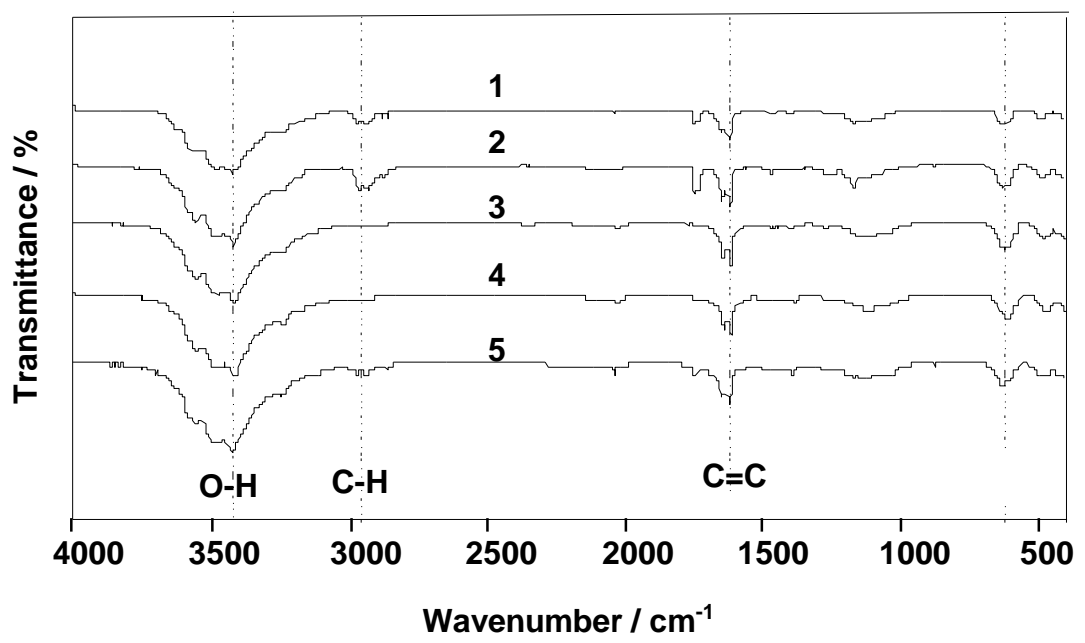

Fig. 4. FTIR spectra of PE extraction

\section{Summary}

In this study, the extraction characteristics of small molecules from peanut shell with ethanol, acetone and petroleum ether were investigated. The effect of ethanol extraction was better, the total yield of ethanol extraction was $31.6 \%$, the yield of acetone extraction was $24.4 \%$, and petroleum ether extraction was $17.4 \%$. The reason may be that ethanol is a polar molecule, and the molecule is 
small enough to penetrate into network macromolecules, allowing organic components to be extracted. FTIR analysis showed that ethanol was better than acetone and petroleum ether in the extraction of hydroxyl, benzene, $\mathrm{C}-\mathrm{O}$ and aliphatic $\mathrm{C}-\mathrm{H}$ structure, while the extraction of containing $\mathrm{C}=\mathrm{O}$ group was weaker than the other two solvents. The research has important basic theoretical significance in developing peanut shell with high added value.

\section{Acknowledgement}

This work was supported by the China Building Material Federation (2014-M3-4), Xuzhou Information Institute (XKQ016), Innovative Training Program for College Students of Xuzhou University of Technology (XCX2017155), Innovation and Entrepreneurship for College Students of Xuzhou University of Technology (2017042) and Open laboratory project of Xuzhou University of Technology.

\section{References}

[1] X. Han, H.X. Chen, J.J. Liu, H.H. Liu, P. Wang, K. Huang, C. Li, S.Y. Chen and Y. Yang, A peanut shell inspired scalable synthesis of three-dimensional carbon Coated porous silicon particles as an anode for lithium-ion batteries, Electrochimica Acta, 156 (2015) 11-19.

[2] J. Ding, H.L Wang, Z. Li, K. Cui, X.H Tan, D. Karpuzov, A. Kohandehghan and D. Mitlin, Peanut shell hybrid sodium ion capacitor with extreme energy-power rivals lithium ion capacitors, Energy Environ. Sci., 8 (2015) 941-955.

[3] T. Xu and X.Q. Liu, Peanut Shell Activated Carbon: Characterization, surface Modification and adsorption of $\mathrm{Pb}^{\wedge} 2+$ from aqueous solution, J. Chemical Engineering, 16 (2008) 401-406.

[4] C.R. Lnis, B. Antonio and E.G. Elio, Peanut shell activated carbon: adsorption capacities for copper ( II ), zinc ( II ), nickel ( II ) and chromium (VI) ions from aqueous solutions, Adsorp. Sci. Technol., 22 (2004) 237- 243.

[5] E.G. Elio and F.G. Luise, Kinetics of phenol removal from aqueous solution by adsorption onto peanut shell acid-activated carbon, Adsorp. Sci. Technol., 23(2005) 289-301.

[6] C.R. Luis, B. Antonio and E.G. Elio, Acid-activated carbons from peanut shells: Synthesis, characterization and uptake of organic compound from aqueous solutions, Adsorp. Sci. Technol., 21 (2003) 617-626. 